\title{
cost-effectiveness of an early intervention service for people with psychosis
}

Paul McCrone, Tom K. J. Craig, Paddy Power and Philippa A. Garety

\section{Background}

There is concern that delaying treatment for psychosis may have a negative impact on its long-term course. A number of countries have developed early intervention teams but there is limited evidence regarding their cost-effectiveness.

\section{Aims \\ To compare the costs and cost-effectiveness of an early intervention service in London with standard care.}

\section{Method}

Individuals in their first episode of psychosis (or those who had previously discontinued treatment) were recruited to the study. Clinical variables and costs were measured at baseline and then at 6- and 18-month follow-up. Information on quality of life and vocational outcomes were combined with costs to assess cost-effectiveness.

\section{Results}

A total of 144 people were randomised. Total mean costs were $£ 11685$ in the early intervention group and £14062 in the standard care group, with the difference not being significant $(95 \% \mathrm{Cl}-£ 8128$ to $£ 3326)$. When costs were combined with improved vocational and quality of life outcomes it was shown that early intervention would have a very high likelihood of being cost-effective.

\section{Conclusions}

Early intervention did not increase costs and was highly likely to be cost-effective when compared with standard care.

\section{Declaration of interest}

None.

previous contacts then they must have immediately disengaged without any treatment. People were excluded if they had organic psychosis or a primary diagnosis of drug or alcohol misuse. Data were collected between 2000 and 2003 .

Participants were identified by screening referrals for possible psychosis and this was then checked via a clinical interview using the Schedules of Clinical Assessment in Neuropsychiatry. ${ }^{11}$ Those with confirmed psychosis who were eligible for the study and who consented were randomised (using sealed envelopes for concealment) in blocks of two to six people to receive community input from the Lambeth Early Onset (LEO) team or from standard services. This was followed by a baseline interview and follow-up interviews at 6 and 18 months. Many participants were in-patients at the time of referral and care from the LEO team or standard care services began after this admission.

The LEO team provided assertive outreach to those with newly diagnosed psychosis. The LEO service did not set out to detect early signs of psychosis. The focus of the team was limited to maximising engagement, psychosocial recovery and preventing relapse. It consisted of ten staff members (including psychiatrists, psychologists, occupational therapists, nurses and healthcare assistants). Interventions for people with early psychosis were provided including low-dose medication regimes, cognitivebehavioural therapy, family therapy and vocational rehabilitation. Standard care was provided by community mental health teams who had no extra training in dealing with early psychosis. The key contrast between the two interventions was that LEO provided assertive follow-up provided by a multidisciplinary team dedicated to managing early psychosis compared with the usual care model where follow-up is provided by a generic mental health team and first-episode cases are mixed in with a spectrum of other disorders.

\section{Outcome measures}

The primary outcome measures in the main trial were rates of relapse and hospitalisation. This presents problems for the 
economic evaluation as hospitalisations are also a key cost component. The secondary outcome measures used in the study (see Garety et al) ${ }^{6}$ included two that are of particular relevance for the economic analyses - quality of life and vocational recovery. The former was measured with the Manchester Short Assessment of Quality of Life (MANSA). ${ }^{12}$ Vocational recovery was defined as a return to or taking up full-time independent employment or full-time education and was rated from case-note information. These were both used to generate cost-effectiveness acceptability curves (see below).

In the initial analyses we did not adjust for any differences between the groups in background characteristics. In secondary analyses such adjustment has been made using a linear regression model for the MANSA and a logistic regression model for vocational recovery. Variables included were age, gender, ethnicity, employment, diagnosis and whether this was a first or second episode (but with no continued treatment) of psychosis.

\section{Service use and costs}

A public sector (health, social care and criminal justice) perspective was adopted for the calculation of costs. Service use was measured using an adapted version of the Client Service Receipt Inventory (CSRI). ${ }^{13}$ The CSRI has been used in numerous economic evaluations of mental health services in the UK and internationally. Services included hospital-based care (in-patient and out-patient), primary care services, social care services and contacts with the criminal justice system. Participants were asked whether they had used specific services during the 6-month period prior to: baseline assessment; 6-month follow-up; and 18-month follow-up. Although service use was not collected for the period between 6 and 12 months, data were available from the administrative system of the local hospital on in-patient stays for the whole of the 18-month period following randomisation.

Service use data were combined with appropriate unit cost information for 2003/4. This was primarily obtained from a nationally recognised source. ${ }^{14}$ These costs were used in preference to National Health Service reference costs (which are largely confined to hospital care). They include elements for salaries, overheads, capital and training, and allow a cost of face-to-face contact to be estimated. Other sources were used for police and prison costs. ${ }^{15,16}$ In the absence of other data, police cell costs were assumed to be the same as prison costs (although this may be an unrealistic assumption, very few individuals spent time in either prison or police cells). Total service costs over the 18-month follow-up period were calculated by: adding the non-in-patient costs for the 6-month period prior to 6- and 18-month followup; multiplying these by 1.5 ; and adding these costs to the in-patient costs. Baseline costs were calculated by adding the costs of services used during the period prior to randomisation and also the index admission (which often ended after the randomisation date but which was not under the control of the LEO team). Given the relatively short follow-up period costs were not discounted.

Eighteen-month costs were compared, controlling for baseline, using a bootstrapped regression model to account for the likely skewed distribution of the residuals. Secondary analyses were conducted to adjust for the same variables as were used for the MANSA and vocational recovery analyses.

\section{Cost-effectiveness}

The cost-effectiveness of early intervention compared with standard services was assessed using the net-benefit approach. ${ }^{17}$ There is a theoretical, but unknown, value (represented by the term $\lambda$ below) that society would place on a one-unit improvement in quality of life or of someone making a vocational recovery. The net benefit to society can be defined as:

$$
\mathrm{NB}=(\lambda \times \mathrm{E})-\mathrm{SC}
$$

where NB is the net benefit, $\mathrm{E}$ is the effectiveness (i.e. improvement in quality of life or vocational recovery rate) and SC is the service costs.

We estimated net benefits for all participants in the sample by assuming different values for $\lambda$ ranging from $\mathfrak{E} 0$ to $\mathfrak{E} 10000$ in

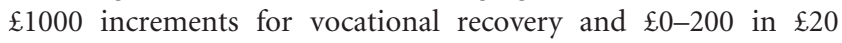
increments for a one-point change on the MANSA. Regression models were then used to determine the mean difference in net benefit between the early intervention and standard services for every value of $\lambda$. For each model, 1000 regression coefficients for the early intervention/standard service variable were generated using bootstrapping, and the proportion of these that were greater than zero indicated the probability that early intervention was the most cost-effective option. These probabilities were subsequently used to generate cost-effectiveness acceptability curves. ${ }^{18}$ Unfortunately no guidance was available for choosing the $\lambda$ values. The range for the vocational recovery outcome was felt appropriate as such recovery could lead to production increases that would (over a period of time) likely be valued in $£ 1000$ s. The MANSA has a wide range, hence relatively small increments were used for unit improvements. As with the outcomes and costs, we conducted secondary analyses by making adjustment for baseline costs and individual characteristics by including these variables in the regression models.

\section{Results}

\section{Participants}

Of 319 people presenting to services, 144 met the inclusion criteria and were randomised ( 71 to early intervention and 73 to standard care). Craig et al report the characteristics of the sample and so only a summary is given here. ${ }^{5}$ The mean age was $26($ s.d. $=6)$ years in the early intervention group and $27($ s.d. $=6)$ years in the standard care group. Men accounted for $55 \%$ and $74 \%$ of the groups respectively. The majority ( $86 \%$ early intervention, $71 \%$ standard care) were in their first episode of psychosis. Of the individuals in the early intervention group, $62 \%$ were from Black and minority ethnic groups, whereas the figure was $75 \%$ for people in the standard care group. Only $18 \%$ of early intervention participants and $19 \%$ of standard care participants were in full- or part-time employment. Schizophrenia was the most common diagnosis ( $72 \%$ early intervention, $67 \%$ standard care).

\section{Service use and costs}

Data on in-patient use at entry to the study were available on 69 early intervention (97\%) and 70 (96\%) standard care participants. Of these, 43 (62\%) early intervention and 43 (61\%) standard care participants had an initial admission. Individuals in the early intervention group spent a mean (s.d.) 52.3 (94.4) days in hospital during this baseline period compared with 44.0 (90.8) days in the standard care group. This resulted in mean (s.d.) costs of $£ 8989$ (16 232) and $\mathfrak{E} 7573$ (15612) respectively.

At baseline, data on services (other than psychiatric in-patient care) were available for all participants. Patterns of service use were broadly similar between the two groups although a slightly higher percentage of people in the early intervention group had contacts with counsellors and community mental health nurses (Table 1). Around two-thirds in each group had seen a general practitioner (GP) and most were on some form of medication. 
Table 1 Number (\%) of participants using services in past 6 months

\begin{tabular}{|c|c|c|c|c|c|c|}
\hline \multirow[b]{2}{*}{ Service } & \multicolumn{2}{|c|}{ Baseline, $n$ (\%) } & \multicolumn{2}{|c|}{ 6-month follow-up, $n$ (\%) } & \multicolumn{2}{|c|}{ 18-month follow-up, $n$ (\%) } \\
\hline & $\begin{array}{l}\text { Early intervention } \\
\qquad(n=71)\end{array}$ & $\begin{array}{c}\text { Standard care } \\
\quad(n=73)\end{array}$ & $\begin{array}{l}\text { Early intervention } \\
\qquad(n=71)\end{array}$ & $\begin{array}{c}\text { Standard care } \\
\quad(n=72)\end{array}$ & $\begin{array}{l}\text { Early intervention } \\
\qquad(n=67)\end{array}$ & $\begin{array}{l}\text { Standard care } \\
\qquad(n=62)\end{array}$ \\
\hline General practitioner & $48(68)$ & $45(62)$ & $33(47)$ & $29(40)$ & $34(51)$ & $25(40)$ \\
\hline Psychiatrist & $36(51)$ & $35(48)$ & $58(82)$ & $43(60)$ & $51(76)$ & 34 (55) \\
\hline Other doctor & $6(9)$ & 2 (3) & $7(10)$ & 2 (3) & 3 (5) & $0(0)$ \\
\hline Psychologist & $4(6)$ & $1(1)$ & $20(28)$ & $2(3)$ & $16(24)$ & $5(8)$ \\
\hline Healthcare assistant & 1 (1) & $0(0)$ & $16(23)$ & 2 (3) & $18(27)$ & 1 (2) \\
\hline Counsellor/therapist & $8(11)$ & 1 (1) & $4(6)$ & 1 (1) & 1 (2) & $0(0)$ \\
\hline Social worker & $14(20)$ & $15(21)$ & $28(39)$ & $23(32)$ & $8(12)$ & $13(21)$ \\
\hline Community mental health nurse & $18(25)$ & $11(15)$ & $65(92)$ & $40(56)$ & $51(76)$ & $34(55)$ \\
\hline Occupational therapist/vocational worker & $4(6)$ & $4(6)$ & $9(13)$ & $7(10)$ & $6(9)$ & $6(10)$ \\
\hline Day care & $6(9)$ & $7(10)$ & $20(28)$ & $9(13)$ & $13(19)$ & $6(10)$ \\
\hline Physical in-patient & $7(10)$ & $0(0)$ & 2 (3) & 2 (3) & 3 (5) & $0(0)$ \\
\hline Residential care & $0(0)$ & $3(4)$ & 2 (3) & $5(7)$ & $1(2)$ & $3(5)$ \\
\hline Drug and alcohol advisor & $0(0)$ & $2(3)$ & $5(7)$ & $1(1)$ & $0(0)$ & $2(3)$ \\
\hline Police & $23(32)$ & $28(38)$ & $14(19)$ & $15(21)$ & $15(22)$ & $13(21)$ \\
\hline Police cell/prison & $0(0)$ & $2(3)$ & 1 (1) & $0(0)$ & $0(0)$ & 2 (3) \\
\hline Medication & $56(79)$ & $58(80)$ & $65(92)$ & $64(89)$ & $51(76)$ & $46(74)$ \\
\hline
\end{tabular}

In the 6 months following randomisation, data on these services were available for all early intervention and 72 (99\%) standard care participants. There was a clear difference in use of services with more in the early intervention group having contacts with psychiatrists, psychologists, healthcare assistants, community mental health nurses and day-care services. This greater level of service use had been maintained by the 18 -month follow-up. Here, data were available for 67 people in the $(94 \%)$ early intervention group and $62(85 \%)$ in the standard care group.

For those in contact with specific services the intensity of service use was similar (Table 2). However, the mean number of contacts with healthcare assistants, community mental health nurses and day-care services was higher in the early intervention group in the 6 months following randomisation. In the 6-month to 18-month follow-up, social worker contacts were greater for those using this service in the early intervention group, whereas the intensity of community mental health worker contacts was now greater in the control group.
Interpretation of the cost differences (for all participants) shown in Table 3 is problematic because of the large standard deviations. However, clear differences occur and these are in line with the service use differences already summarised. In the 6 months following randomisation the costs of psychiatrists, psychologists, healthcare assistants, counsellors and community mental health nurses were all higher in the early intervention group. By 18-month follow-up the costs of psychiatrists, psychologists and healthcare assistants continued to be higher for the early intervention group.

Total costs at baseline and over the 18-month follow-up period are shown in Table 4. Follow-up costs could be calculated for $65(92 \%)$ early intervention and $61(84 \%)$ standard care participants. No differences in characteristics between those for whom 18-month costs could be calculated and those for whom they could not were significant. Costs at follow-up were $£ 2318$ lower in the early intervention group (controlling for baseline costs), which was not statistically significant (bootstrapped $95 \%$

\begin{tabular}{|c|c|c|c|c|c|c|}
\hline \multirow[b]{2}{*}{ Service } & \multicolumn{2}{|c|}{ Baseline, mean (s.d.) } & \multicolumn{2}{|c|}{ 6-month follow-up, mean (s.d.) } & \multicolumn{2}{|c|}{ 18-month follow-up, mean (s.d.) } \\
\hline & $\begin{array}{l}\text { Early intervention } \\
\qquad(n=71)\end{array}$ & $\begin{array}{l}\text { Standard care } \\
\qquad(n=73)\end{array}$ & $\begin{array}{l}\text { Early intervention } \\
\qquad(n=71)\end{array}$ & $\begin{array}{l}\text { Standard care } \\
\quad(n=72)\end{array}$ & $\begin{array}{l}\text { Early intervention } \\
\qquad(n=67)\end{array}$ & $\begin{array}{c}\text { Standard care } \\
\qquad(n=62)\end{array}$ \\
\hline General practitioner & $2.7(2.4)$ & $2.7(3.7)$ & $3.1(2.8)$ & $3.1(4.5)$ & $2.8(2.8)$ & $3.0(3.2)$ \\
\hline Psychiatrist & $4.1(6.8)$ & $2.4(2.9)$ & $4.4(3.5)$ & $4.5(3.3)$ & $4.6(3.8)$ & $3.1(2.4)$ \\
\hline Other doctor & $1.8(2.0)$ & $1.5(0.7)$ & $2.6(2.0)$ & $1.0(0.0)$ & $1.3(0.6)$ & - \\
\hline Psychologist & $2.0(1.4)$ & $1.0(-)$ & $4.1(5.1)$ & $2.0(1.4)$ & $6.2(5.7)$ & $4.2(3.1)$ \\
\hline Healthcare assistant & $1.0(-)$ & - & $8.4(7.4)$ & $1.0(0.0)$ & $4.0(3.3)$ & $2.0(-)$ \\
\hline Counsellor/therapist & $3.6(1.6)$ & $5.0(-)$ & $6.5(4.4)$ & $1.0(-)$ & $1.0(-)$ & - \\
\hline Social worker & $2.5(2.7)$ & $1.4(0.6)$ & $4.3(5.2)$ & $5.0(6.2)$ & $6.9(6.8)$ & $3.0(1.9)$ \\
\hline Community mental health nurse & $3.3(2.9)$ & $3.5(2.9)$ & $11.6(7.3)$ & $7.7(7.5)$ & $7.0(5.6)$ & $10.0(16.1)$ \\
\hline Occupational therapist/vocational worker & $1.3(0.5)$ & $4.5(7.0)$ & $5.4(7.7)$ & $4.3(3.7)$ & $2.5(3.7)$ & $7.7(5.8)$ \\
\hline Day care & $16.5(33.2)$ & $6.6(5.4)$ & $6.7(10.3)$ & $2.2(1.4)$ & $5.7(5.6)$ & $6.7(8.8)$ \\
\hline Physical in-patient & $5.6(5.6)$ & - & $4.5(5.0)$ & $2.0(1.4)$ & $5.0(6.9)$ & - \\
\hline Drug and alcohol advisor & - & $1.5(0.7)$ & $2.8(3.0)$ & $2.0(-)$ & - & $3.5(3.5)$ \\
\hline Police & $1.2(0.5)$ & $1.3(1.2)$ & $1.4(0.5)$ & $1.3(0.5)$ & $1.1(0.3)$ & $1.2(0.4)$ \\
\hline Police cell/prison & - & $2.0(1.4)$ & $1.0(-)$ & - & - & $11.0(4.2)$ \\
\hline
\end{tabular}


Table 3 Mean (s.d.) cost of services used in past 6 months $(2003 / 4 \mathrm{f}$ sterling)

\begin{tabular}{|c|c|c|c|c|c|c|}
\hline \multirow[b]{2}{*}{ Service } & \multicolumn{2}{|c|}{ Baseline, mean (s.d.) } & \multicolumn{2}{|c|}{ 6-month follow-up, mean (s.d.) } & \multicolumn{2}{|c|}{ 18-month follow-up, mean (s.d.) } \\
\hline & $\begin{array}{l}\text { Early intervention } \\
\qquad(n=71)\end{array}$ & $\begin{array}{c}\text { Standard care } \\
\quad(n=73)\end{array}$ & $\begin{array}{l}\text { Early intervention } \\
\qquad(n=71)\end{array}$ & $\begin{array}{c}\text { Standard care } \\
\quad(n=72)\end{array}$ & $\begin{array}{l}\text { Early intervention } \\
\qquad(n=67)\end{array}$ & $\begin{array}{c}\text { Standard care } \\
\qquad(n=62)\end{array}$ \\
\hline General practitioner & $56(105)$ & $40(73)$ & $35(60)$ & $28(69)$ & $45(84)$ & $42(115)$ \\
\hline Psychiatrist & $303(573)$ & $182(361)$ & $600(573)$ & $437(740)$ & $487(469)$ & 241 (341) \\
\hline Other doctor & $9(46)$ & $2(11)$ & $21(80)$ & $4(23)$ & $6(30)$ & $0(0)$ \\
\hline Psychologist & $8(39)$ & $0.5(4.0)$ & $77(224)$ & $3(25)$ & 122 (359) & $23(97)$ \\
\hline Healthcare assistant & $1(4)$ & $0(0)$ & $30(90)$ & $0.3(1.5)$ & $14(34)$ & $0.3(2.3)$ \\
\hline Counsellor/therapist & $12(36)$ & $2(19)$ & $10(52)$ & $0.5(3.9)$ & $0.5(4.0)$ & $0(0)$ \\
\hline Social worker & $38(132)$ & $15(34)$ & $116(333)$ & $87(258)$ & $50(206)$ & $41(94)$ \\
\hline Community mental health nurse & $42(142)$ & $18(54)$ & 447 (334) & $176(298)$ & $206(260)$ & $232(506)$ \\
\hline Occupational therapy/vocational worker & $2(8)$ & $14(116)$ & $23(117)$ & $11(43)$ & $6(28)$ & $12(47)$ \\
\hline Day care & 30 (234) & $8(46)$ & $37(152)$ & $3(13)$ & $17(51)$ & $13(82)$ \\
\hline Physical in-patient & $161(684)$ & $0(0)$ & $37(276)$ & $16(107)$ & $65(461)$ & $0(0)$ \\
\hline Residential care & $0(0)$ & 297 (1519) & 119 (993) & 524 (1945) & $132(1082)$ & 257 (1154) \\
\hline Drug and alcohol advisor & $0(0)$ & $0.2(1.5)$ & $4(24)$ & $0.3(2.8)$ & $0(0)$ & $1(9)$ \\
\hline Police & $6(9)$ & $7(14)$ & $4(8)$ & $4(8)$ & $3(7)$ & $3(7)$ \\
\hline Police cell/prison & $0(0)$ & $4(26)$ & $1(8)$ & $0(0)$ & $0(0)$ & $25(142)$ \\
\hline Medication & $81(198)$ & $86(161)$ & 414 (320) & 447 (442) & $336(415)$ & 378 (451) \\
\hline
\end{tabular}

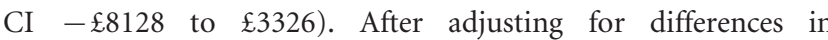
participant characteristics the difference was reduced to $\mathfrak{E} 1756$ (bootstrapped $95 \%$ CI $-£ 4714$ to $£ 8226$ ).

\section{Cost-effectiveness}

Data on full vocational recovery by 18 months were available for 64 people in the early intervention group and 62 in the standard care group. The sample for whom we had data were similar to those for whom we did not, although $20(16 \%)$ of the former were in work at baseline compared with $6(35 \%)$ of the latter (Fisher's exact test, $P=0.088)$. In total, $21(33 \%)$ early intervention participants and $13(21 \%)$ standard care participants had made a full vocational recovery, which was not statistically significant at conventional levels (Fisher's exact test, $P=0.162$ ). After adjusting for participant characteristics using a logistic regression the odds ratio for the group variable was 1.47 (indicating that early intervention resulted in greater levels of vocational recovery) but this was non-significant $(P=0.402)$. Early intervention was dominant (less expensive and more effective) based on the point estimates, but there is uncertainty around these values. If society would not be willing to pay anything for an individual who makes a full or partial vocational recovery then we can see from Fig. 1 there is still a $76 \%$ likelihood of early intervention being the most cost-effective option and this increases steadily as the willingness to pay value is increased. However, these probabilities fall slightly after adjusting for baseline costs and participant characteristics. Here, however, there remains a $66 \%$ likelihood of early intervention being cost-effective even if a zero value is placed on someone making a vocational recovery.

Manchester Short Assessment of Quality of Life scores were available on fewer individuals at 18 months: 52 (73\%) early intervention, $40(55 \%)$ standard care. This response rate was significantly different (Fisher's exact test, $P=0.025$ ). No other differences between those with and without MANSA scores were significantly different. The mean (s.d.) scores were 59.3 (12.6) for early intervention and 53.3 (12.4) for standard care. This difference of six points is statistically significant ( $t$-test, $P=0.025)$. After adjusting for participant characteristics the difference remained at six points but with a reduction in significance $(P=0.050)$. Again, early intervention was the dominant option. Figure 2 shows that with a value of $\mathfrak{E} 0$ placed on a unit difference in the MANSA there is a $92 \%$ likelihood of early intervention being the most cost-effective option, and if

Table 4 In-patient days, in-patient costs and total costs at baseline and 18-month follow-up and quality of life and

vocational outcomes at 18 -month follow-up

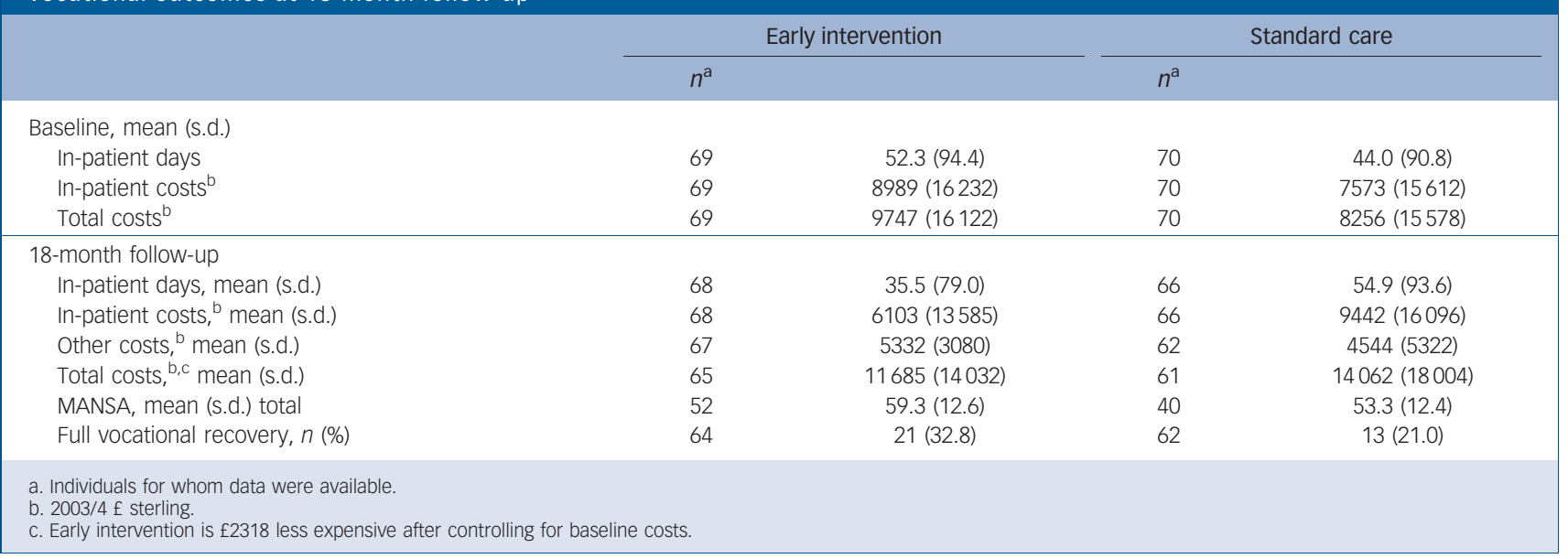




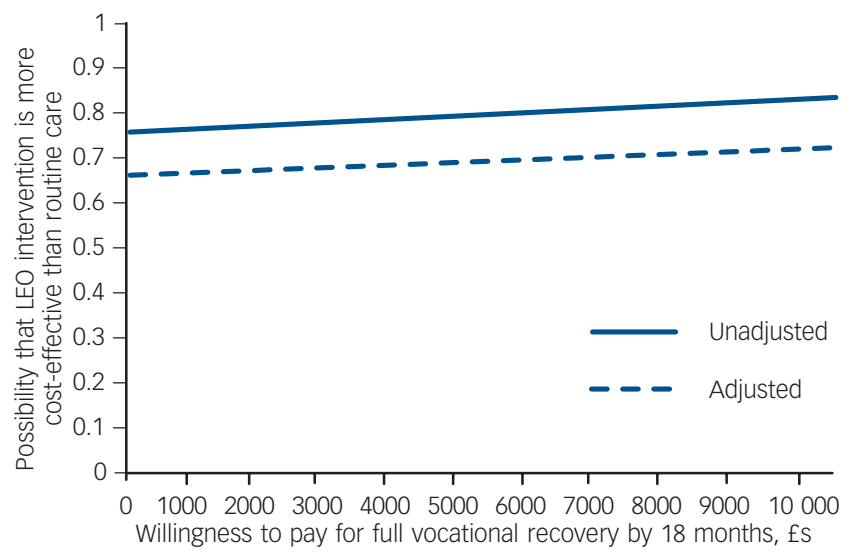

Fig. 1 Cost-effectiveness acceptability curve showing probability that specialised care is more cost-effective than usual care at achieving full vocational recovery. LEO, Lambeth Early Onset.

the value rises then (as with vocational recovery) this likelihood increases steadily. As with the analysis on vocational recovery, the probability falls after adjusting for baseline costs and participant characteristics but remains high.

\section{Discussion \\ Main findings}

The early intervention service evaluated in this study provided assertive community treatment to participants who otherwise may have had problems engaging with services. As such we might expect the cost of community-based services to be higher as a result of early intervention but this increase could be offset if the early intervention service results in reduced hospitalisations. To some extent that is what the study revealed. Contacts with psychiatrists, psychologists, healthcare assistants, community mental health nurses and day-care services were all more likely for individuals in the early intervention group during the first 6 months after randomisation. In-patient costs for the early intervention group during the 18-month follow-up period were around two-thirds of the costs for the standard care group. However, the overall cost difference in favour of early intervention was not statistically significant.

\section{Comparisons with other studies}

Other early intervention evaluations have demonstrated reduced resource use. A UK study recently examined the impact on bed days of an early intervention service. ${ }^{7}$ Bed days before the service was introduced were significantly greater than subsequently, with the cost savings sufficient to pay for the team itself. In Australia, Mihalopoulos et al evaluated a psychosis prevention service (as opposed to a service for those already with psychosis as here) and found costs to be less than for a period when the service did not operate because of reductions in in-patient service use even though community costs increased. ${ }^{9}$ Recently, a study from the same group has shown that short-term cost increases associated with preventative interventions are offset by reduced out-patient costs in the longer term. ${ }^{19}$ Elsewhere, Goldberg et al compared hospital costs for people receiving early intervention and those receiving standard care before the service was introduced. ${ }^{8}$ These costs were reduced but it was not possible to show that this was because of the early intervention service. An evaluation of assertive community treatment for those with first-episode psychosis revealed significantly fewer days in hospital over a 1-year follow-up period, although the difference after
2 years was not statistically significant. ${ }^{4}$ Finally, Valmaggia et al have produced a model to assess the impact on costs of an early detection service in south London. ${ }^{10}$ Over a 12 -month period the costs do not differ compared with usual care but over 18 months the costs are reduced as a result of less in-patient care. Although we also show cost savings, the non-significance of the result means that cost increases are also possible. Many of the previous studies used a pre-post design and such changes might have been expected. The controlled design here has produced findings that are arguably more robust. In addition, standard care services may have been relatively well developed which makes cost savings more challenging to demonstrate.

Early intervention resulted in a higher rate of vocational recovery than standard care and, although this was also not statistically significant, when combined with the cost data revealed that there was a very high likelihood that early intervention would be cost-effective - even if a zero value was placed on someone recovering vocationally. Although we do not know what value society would place on someone getting into work or training, it is reasonable to assume that this would be greater than zero. Similarly, the difference in quality of life combined with costs suggests a very high likelihood of early intervention being cost-effective. Again, we do not know what the value of a quality of life improvement is but in a sense this is irrelevant given the curve shown in Fig. 2.

\section{Limitations}

There are a number of limitations to this study. First, with the exception of in-patient care the service costs relied on information collected from individuals. This was required in order to obtain the breadth of service use data required but accuracy of recall may be a concern. However, studies have been conducted that have shown such a method to have good levels of reliability. ${ }^{20,21}$ Second, one of the primary outcome measures used in the overall trial was hospitalisations. This is also a cost and so is not straightforward to use in a cost-effectiveness analysis. Therefore we used two secondary outcome measures in the analyses - quality of life and vocational rehabilitation - which both do have relevance for economic evaluations. Third, although we felt it appropriate to use these outcome measures, the analyses based on them were challenging to interpret as we do not know what the threshold value (or range of values for the cost-effectiveness acceptability curves) is for these by which cost-effectiveness can be determined. Fourth, the study was conducted between 2000 and 2003 and services (particularly standard care) may have changed since then.

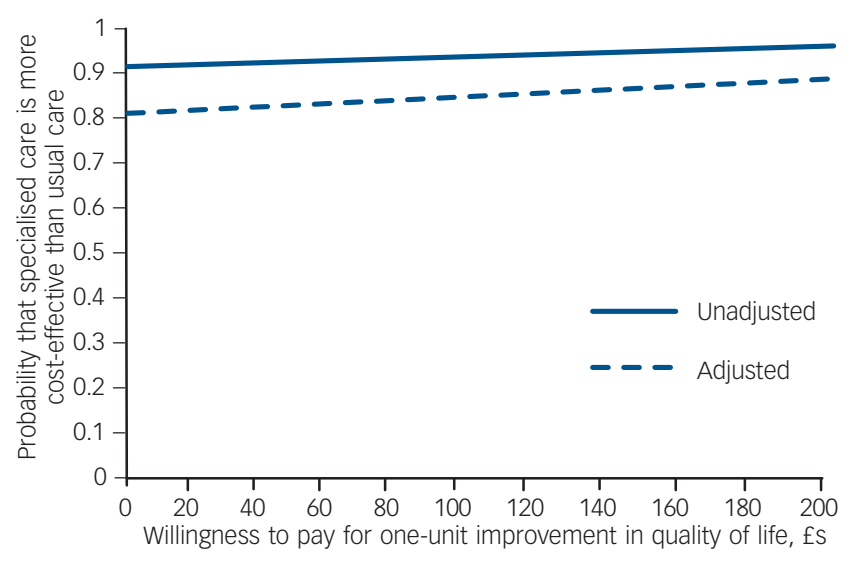

Fig. 2 Cost-effectiveness acceptability curve showing probability that specialised care is more cost-effective than usual care at improving quality of life. 
Fifth, these were complete case analyses. We did not replace missing outcomes or costs with imputed values and so there may be some bias in the results if there are differences between those individuals who dropped out and those who were completers. Sixth, cost data (other than for psychiatric in-patient care) were not available between 6 and 12 months and therefore values were imputed for this period.

Seventh, no measure of quality-adjusted life years (QALYs) was included. Quality-adjusted life years are used to compare interventions across different conditions and consequently are of importance to those responsible for making recommendations about how healthcare funds should be distributed. In England, the National Institute for Health and Clinical Excellence has issued guidance on the methods used in evaluations and recommends the use of QALYs, ${ }^{22}$ and also the EQ-5D to generate these. ${ }^{23}$ The project here was designed prior to this guidance being issued, but there are in any case some concerns about the use of QALYs in mental healthcare evaluations. ${ }^{24}$ One potential problem is that existing measures are not sensitive to change in mental health status. ${ }^{25}$ However, recently Barton et al have suggested that EQ-5D scores do vary in ways that reflect different levels of psychosis symptomatology, ${ }^{26}$ and a large European study of the cost-utility of treatments for psychosis found it an acceptable method. ${ }^{27}$ There is however some evidence ${ }^{25}$ to suggest that the EQ-5D may not have as good statistical properties as the SF- $6 \mathrm{D}^{28}$ in this patient group. Future studies of early intervention should include QALY measures and the EQ-5D should be compared with alternatives.

Finally, the data here relate to an 18-month follow-up period. Gafoor and colleagues in this issue have examined readmission rates for participants in this sample after 5 years. They show no advantage for the early intervention group and therefore the long-term impact of early intervention on hospital use may not be substantial. However, that study did not link costs with outcomes over the longer period.

This study has shown that early intervention (in the form of an assertive follow-up team) in this part of London did not lead to increased service costs. Although hospitalisation was reduced, the overall costs were not statistically significant from those of usual care. However, early intervention appeared to be cost-effective with even small values placed on improved quality of life and vocational outcomes.

Paul Mccrone, PhD, Tom K. J. Craig, FRCPsych, Health Service and Population Research Department, Institute of Psychiatry, King's College London; Paddy Power FRANZCP, South London and Maudsley NHS Foundation Trust: Philippa A. Garety, PhD, FBPsS, Department of Psychology, Institute of Psychiatry, King's College London, UK

Correspondence: Paul McCrone, Centre for the Economics of Mental Health, PO 24, Health Service and Population Research Department, David Goldberg Centre, Institute of Psychiatry, De Crespigny Park, London SE5 8AF, UK. Email: p.mccrone@iop.kcl.ac.uk

First received 9 Mar 2009, final revision 24 Sep 2009, accepted 7 Oct 2009

\section{Funding}

The study was funded by a grant from the Directorate of Health and Social Care for London R\&D Organisation and Management Programme.

\section{References}

1 McGrath J, Saha S, Chant D, Welham J. The epidemiology of schizophrenia: a concise overview of incidence, prevalence, and mortality. Epidemiol Rev 2008; 30: 67-76.

2 Kirkbride J, Fearon P, Morgan C, Dazzan P, Morgan K, Tarrant J, et al. Heterogeneity in incidence rates of schizophrenia and other psychotic syndromes: findings from the 3-center AESOP study. Arch Gen Psychiatry 2006; 63: 250-8

3 Marshall $\mathrm{M}$, Lewis $\mathrm{S}$, Lockwood $\mathrm{A}$, Drake $\mathrm{R}$, Jones $\mathrm{P}$, Croudace $\mathrm{T}$. Association between duration of untreated psychosis and outcome in cohorts of first-episode patients: a systematic review. Arch Gen Psychiatry 2005; 62: 975-83.

4 Petersen L, Jeppesen P, Thorup A, Øhlenschlæger J, Christensen TØ, Krarup $\mathrm{G}$, et al. A randomised multicentre trial of integrated versus standard treatment for patients with a first episode of psychotic illness. BMJ 2005; 331: $602-5$.

5 Craig TKJ, Garety P, Power P, Rahaman N, Colbert S, Fornells-Ambrojo M, et al. The Lambeth Early Onset (LEO) Team: randomised controlled trial of the effectiveness of specialised care for early psychosis. BMJ 2004; 329: 1067.

6 Garety PA, Craig TKJ, Dunn G, Fornells-Ambrojo M, Colbert S, Rahaman, et al. Specialised care for early psychosis: symptoms, social functioning, and patient satisfaction. Randomised controlled trial. Br J Psychiatry 2006; 188 37-45.

7 Dodgson G, Crebbin K, Pickering C, Mitford E, Brabban A, Paxton R. Early intervention in psychosis service and psychiatric admissions. Psychiatr Bull 2008; 32: 413-6.

8 Goldberg K, Norman R, Hoch JS, Schmitz N, Windell D, Brown, et al. Impact of a specialized early intervention service for psychotic disorders on patient characteristics, service use, and hospital costs in a defined catchment area. Can J Psychiatry 2006; 51: 895-903.

9 Mihalopoulos C, McGorry PD, Carter RC. Is phase-specific community orientated treatment of early psychosis an economically viable method for improving outcome? Acta Psychiatr Scand 1999; 100: 47-55.

10 Valmaggia L, McCrone P, Knapp M, Woolley JB, Broome MR, Tabraham P, et al. Economic impact of early intervention in people at high risk of psychosis. Psychol Med 2009; 39: 1617-26.

11 Wing JK, Barbour T, Brugha T, Burke J, Cooper JE, Giel R, et al. SCAN. Schedules for Clinical Assessment in Neuropsychiatry. Arch Gen Psychiatry 1990; 47: 589-93.

12 Priebe S, Huxley $P$, Knight S, Evans J. Application and results of the Manchester Short Assessment of Quality of Life (MANSA). Int J Soc Psychiatry 1999; 45: 7-12.

13 Beecham J, Knapp M. Costing psychiatric interventions. In Measuring Mental Health Needs (ed G Thornicroft): 200-24. Gaskell, 2001.

14 Netten A, Curtis L. Unit Costs of Health and Social Care. PSSRU, 2004

15 HM Prison Service. Annual Report and Accounts 2003-2004. HM Prison Service, 2004 (http://www.hmprisonservice.gov.uk/resourcecentre/ publicationsdocuments/index.asp?cat=38).

16 Finn W, Hyslop J, Truman C. Mental Health, Multiple Needs and the Police. Revolving Doors Agency, 2000.

17 Briggs AH. A Bayesian approach to stochastic cost-effectiveness analysis. Int J Technol Assess Health Care 2001; 17: 69-82.

18 Hoch J, Briggs A, Willan A. Something old, something new, something borrowed, something BLUE: a framework for the marriage of health econometrics and cost-effectiveness analysis. Health Economics 2002 11: $415-30$

19 Phillips L, Cotton S, Mihalopoulos C, Shih S, Yung AR, Carter R, et al. Cost implications of specific and non-specific treatment for young persons at ultra high risk of developing a first episode of psychosis. Early Interv Psychiatry 2009; 3: 28-34.

20 Calsyn RJ, Allen G, Morse GA, Smith R, Tempelhoff B. Can you trust selfreport data provided by homeless mentally ill individuals? Eval Rev 1993; 17: 353-66.

21 Goldberg RW, Seybolt DC, Lehman A. Reliable self-report of health service use by individuals with serious mental illness. Psychiatr Serv 2002; 53 879-81.

22 National Institute for Health and Clinical Excellence. Guide to the Methods of Technology Appraisal. NICE, 2008.

23 Williams A. The Role of the EUROQOL Instrument in QALY Calculations. Centre for Health Economics, University of York, 1995.

24 Chisholm D, Healey A, Knapp M. QALYs and mental health care. Soc Psychiatry Psychiatr Epidemiol 1997; 32: 68-75.

25 McCrone $P$, Patel A, Knapp M, Schene A, Koeter M, Amaddeo F, et al. A comparison of SF-6D and EQ-5D utility scores in a study of patients with schizophrenia. J Ment Health Policy Econ 2009; 12: 27-31.

26 Barton GR, Hodgekins J, Mugford M, Jones PB, Croudace T, Fowler D. Measuring the benefits of treatment for psychosis: validity and responsiveness of the EQ-5D. Br J Psychiatry 2009; 195: 170-7.

27 Knapp M, Windmeijer F, Brown J, Kontodimas S, Tzivelekis S, Haro JM, et al. Cost-utility analysis of treatment with olanzapine compared with other antipsychotic treatments in patients with schizophrenia in the pan-European SOHO study. Pharmacoeconomics 2008; 26: 341-58.

28 Brazier JE, Roberts JF, Deverill MD. The estimation of a preference based measure of health from the SF-36. J Health Econ 2002; 21: 271-92. 